\title{
Plantar heel pain: should you consult a general practitioner or a podiatrist?
}

\author{
Hylton B Menz 이, 1,2 Matthew P Cotchett (1) , 1,2 \\ Glen A Whittaker (1) 1,2 Shannon E Munteanu, ${ }^{1,2}$ Karl B Landorf (i) 1,2
}

In British Journal of Sports Medicine, Rasenberg and colleagues ${ }^{1}$ report the

${ }^{1}$ Discipline of Podiatry, School of Allied Health, Human Services and Sport, La Trobe University, Melbourne, Victoria, Australia

${ }^{2}$ La Trobe Sport and Exercise Medicine Research Centre, School of Allied Health, Human Services and Sport, La Trobe University, Melbourne, Victoria, Australia

Correspondence to Professor Hylton B Menz, Discipline of Podiatry, School of Allied Health, Human Services and Sport, La Trobe University, Melbourne, VIC 3086, Australia; h.menz@latrobe.edu.au findings of the Soles as Treatment Against Pain in feet (STAP) randomised trial comparing the effectiveness of usual general practitioner (GP) care to referral to a podiatrist for custom insoles or sham insoles in 185 people with plantar heel pain. ${ }^{1}$ After 12 weeks, the usual GP care group reported less pain during activity compared with the custom insole group (assessed using an 11-point Numerical Rating Scale), although this difference was small (less than one point) and did not meet the minimal clinically important difference for this outcome measure. Secondary outcomes favoured the GP group but were mostly small in magnitude. The authors concluded that referral to a podiatrist for custom insoles does not lead to better outcomes compared with usual GP care, and as such, healthcare providers should be 'reserved' in prescribing custom insoles for the treatment of plantar heel pain.

This is a generally well-designed pragmatic trial and the first to be undertaken in a primary care setting, so it makes a valuable contribution to the research literature. Nevertheless, there are three key issues to consider when interpreting the findings of the STAP study which relate to the characteristics of the interventions being compared. First, as acknowledged by the authors, the GPs provided 
more interventions than is typical for the management of this condition in Dutch primary care. ${ }^{2}$ In particular, there was a higher rate of 'heel cups or other biomechanical interventions' (41\%) and corticosteroid injections (15\%), and participants randomised to the GP group also attended more consultations. Therefore, rather than concluding that treatment with custom insoles provides no additional value compared with usual GP care, it could instead be argued that the outcomes were similar between the groups, despite the GPs using a wider range of effective treatment options and seeing participants more frequently.

Second, the prescription and manufacture of the custom insoles were left to the discretion of the 50 different podiatrists involved in the trial. Although the general characteristics of the insoles are reported in the paper, it would appear that no prescription algorithm was used to guide the customisation process. Whether insole customisation is necessary or beneficial is an ongoing debate within the foot orthosis literature, and indeed, our recent systematic review and meta-analysis found no difference in outcomes of custom insoles and generic, prefabricated devices in the treatment of plantar heel pain. ${ }^{3}$ However, the clinical variation allowed in this study, although justifiable in a pragmatic trial, makes it difficult to ascertain exactly what was provided and the underlying reasons for these treatment decisions. For example, the Shore A of the custom insoles ranged from 30 to 60 - an equivalent hardness range from a rubber band to a car tyre-so they are likely to have had variable biomechanical effects.

Third, the authors used a sham insole as a comparator to the custom insole. This is a recommended methodological strategy to minimise ascertainment bias and resentful demoralisation. ${ }^{4}$ However, it is now recognised that when using sham insoles in clinical trials, it is important to either quantify the mechanical effects of the insole or select an insole that is known to provide as minimal effect as possible. ${ }^{5}$ The sham insole in this study was contoured to the participants' individual foot shape based on a three-dimensional scan and incorporated a $12 \mathrm{~mm}$ heel cup-features that are likely to have had at least some mechanical effect. ${ }^{5} 6$ Unfortunately, no biomechanical testing was performed in this trial, so it is not possible to determine the how 'inert' the sham insole was compared with the custom insole.

So, what do these findings mean clinically? In the context of Dutch primary care, Rasenberg and colleagues could perhaps argue that that there is no compelling need for GPs to refer patients with plantar heel pain to podiatrists to be provided with custom insoles, as their outcomes were similar. However, it is important not to oversimplify or overgeneralise this finding - it is only true if GPs in routine primary care provide a similar multifaceted treatment approach to that administered during the trial, and it may not translate to other clinical contexts where GP and podiatry management of plantar heel pain may be quite different. For example, in Australia, GPs primarily manage plantar heel pain with advice and non-steroidal anti-inflammatory medications, ${ }^{7}$ while podiatrists use a wide range of interventions (such as education, stretching, taping and extracorporeal shockwave therapy) in addition to foot orthoses. $^{8}$

In closing, the STAP trial makes a worthwhile contribution to the evidence base for the effectiveness of interventions in managing plantar heel pain, although some caution is required when contextualising the findings.

Twitter Hylton B Menz @hyltonmenz, Glen A Whittaker@GlenAWhittaker and Karl B Landorf @karllandorf

Contributors All authors conceived, reviewed and approved the manuscript. HBM prepared the manuscript.

Funding The authors have not declared a specific grant for this research from any funding agency in the public, commercial or not-for-profit sectors.

Competing interests $\mathrm{HBM}, \mathrm{GAW}$, SEM and KL have been investigators on trials that have evaluated foot orthoses, which have been supplied for free or at a reduced cost.
Patient consent for publication Not required. Provenance and peer review Commissioned; internally peer reviewed.

(c) Author(s) (or their employer(s)) 2021. No commercial re-use. See rights and permissions. Published by BMJ.

A Check for updates

To cite Menz HB, Cotchett MP, Whittaker GA, et al. Br J Sports Med 2021;55:243-248.

Accepted 11 August 2020

Published Online First 2 September 2020

\section{Linked}

http://dx.doi.org/10.1136/bjsports-2019-101409

Br J Sports Med 2021;55:243-248.

doi:10.1136/bjsports-2020-102957

\section{ORCID iDs}

Hylton B Menz http://orcid.org/0000-0002-2045-3846 Matthew P Cotchett http://orcid.org/0000-0001-69665324

Glen A Whittaker http://orcid.org/0000-0002-2102-

7777

Karl B Landorf http://orcid.org/0000-0002-3882-5206

\section{REFERENCES}

1 Rasenberg N, Bierma-Zeinstra SM, Fuit L, et al. Custom insoles versus sham and usual care in patients with plantar heel pain: results of the STAP Study - a randomised controlled trial. Br J Sports Med 2020

2 Rasenberg N, Bierma-Zeinstra SM, Bindels PJ, et al. Incidence, prevalence, and management of plantar heel pain: a retrospective cohort study in Dutch primary care. Br J Gen Pract 2019;69:e801-8.

3 Whittaker GA, Munteanu SE, Menz HB, et al. Foot orthoses for plantar heel pain: a systematic review and meta-analysis. Br J Sports Med 2018:52:322-8.

4 Bonanno DR, Landorf KB, Murley GS, et al. Selecting control interventions for use in orthotic trials: the methodological benefits of sham orthoses. Contemp Clin Trials 2015:42:257.

5 McCormick CJ, Bonanno DR, Landorf KB. The effect of customised and sham foot orthoses on plantar pressures. J Foot Ankle Res 2013;6:19.

6 Bonanno DR, Landorf KB, Menz HB. Pressure-relieving properties of various shoe inserts in older people with plantar heel pain. Gait Posture 2011:33:385-9.

7 Pollack A, Britt H. Plantar fasciitis in Australian general practice. Aust Fam Physician 2015;44:90-1.

8 Morrissey D, Cotchett $M$, J'Bari AS, et al. Management of plantar heel pain: a best practice guide synthesising systematic review with expert clinical Reasoning and patient values. June 22, 2020, Preprint (version 1) available at. Research Square 2020. doi: doi:10.21203/ rs.3.rs-36329/v1. 